\title{
Non-malignant asbestos diseases in workers in an electrochemical plant
}

\section{B HILT}

From the Department of Occupational Medicine, Telemark Sentralsjukehus, 3900 Porsgrunn, Norway

ABSTRACT The prevalence of non-malignant asbestos related disorders was studied in a group of men who had been subjected to different levels of asbestos exposure when working at an electrochemical plant producing nitric acid sometime between 1928 and 1970 . There were 153 men eligible for an initial clinical examination in 1979-80 and that group has been followed up to 1985. Among the cohort members the "accumulated prevalence" of lung fibrosis alone or in combination with pleural plaques and of "pleural plaques only" was $24 \cdot 2 \%$ and $24.8 \%$ respectively. The subgroup with the heaviest exposure had a total prevalence of asbestos related disorders of $82.5 \%$. Only study subjects with lung fibrosis had statistically significant increased prevalences of respiratory symptoms. All subgroups from the study population, however, had mean spirometric values under the age, height, and smoking specific predicted means. Subjects with heavy asbestos exposure and current smoking had a prevalence of three or more respiratory symptoms of $28.8 \%$ compared with $5.6 \%$ among lightly exposed never smokers. Pleural crepitations at chest auscultation were more prevalent among subjects with radiologically visible asbestos related disorders than among study subjects with normal chest $x$ ray films. During the follow up from 1980 to 1985, three cases of lung cancer, two of pleural malignant mesothelioma, and one of stomach cancer were found among the cohort members.

A raised prevalence of radiological signs of nonmalignant asbestos related diseases and of impairment in pulmonary function has been found in surveys of asbestos workers in a variety of occupational settings. In a clinical survey of maintenance workers in the chemical industry Lilis et al observed a $24 \%$ prevalence of subjects with pulmonary fibrosis alone or in combination with pleural plaques, and another $14 \%$ with pleural plaques only. ${ }^{1}$ Apart from the early investigations from Ose and Bittersohl $l^{23}$ the study by Lilis et al seems to be the only one dealing with the occurrence of nonmalignant respiratory disease among asbestos exposed workers in the chemical industry.

In a previous communication the incidence of cancer was presented in a cohort of production and maintenance workers who had been exposed to asbestos in a Norwegian electrochemical plant producing nitric acid. ${ }^{4}$ The aim of the present study was to investigate the prevalence of asbestos related non-malignant lung

Accepted 29 September 1986 disorders in terms of chest $x$ ray abnormalities, respiratory symptoms, and impairment in lung function among cohort members who were still alive in 1979-80 and who have been followed up to 1985 .

\section{Subjects and methods}

\section{ASBESTOS EXPOSURE}

Different types of asbestos were used for various purposes in the production of nitric acid. Large asbestos packings, mainly crocidolite, were used to pack the joints in the incinerators which combusted ammonia into nitrogen oxides. Maintenance work on the 79 incinerators was continuous. Considerable amounts of asbestos dust were generated in the warm dry atmosphere of the incinerator hall when old, dry packing material was renewed. Nitric acid was synthesised at the plant in $4730 \mathrm{~m}$ high outdoor granite towers which were plugged from top to bottom with a mixture of asbestos and waterglass.

The workers who packed the joints and in particular those who prepared the packing material in the so called "fibre hut" were exposed to high concen- 
trations of asbestos dust. Both serpentine and amphibole asbestos was used for this purpose. All other production and maintenance workers at the plant were indirectly exposed to asbestos. Reliable dust measurements at the plant were first carried out after 1970. According to the employees, working conditions had improved a great deal by that time. Consequently, these measurements cannot be considered representative of the working conditions in previous years.

In addition to the exposure to asbestos dust the workers at the plant were also exposed to chemical agents such as nitrous gases, nitric acid vapours, and ammonia.

\section{STUDY POPULATION}

The study cohort comprised of men who had been employed at the nitric acid plant at any time from its beginning in 1928 until 1970 and who were eligible in 1979-80 when the first examination took place. The following groups of workers were included:

(A) twenty men who had mainly been employed in the fibre hut and who had experienced very heavy asbestos exposure;

(B) twenty men who had been heavily exposed when working regularly plugging the joints in the nitric acid towers, and who had also partly been in the fibre hut;

(C) forty seven process operators from the nitric acid towers with mostly indirect exposure;

(D) twenty eight process operators from the incinerator hall with mostly indirect exposure; and

(E) thirty eight other maintenance workers from both the nitric acid towers and the incinerator hall with both moderate and indirect asbestos exposure.

In the present study groups $A$ and $B$ have been combined as a heavily exposed subcohort, and groups $\mathrm{C}, \mathrm{D}$, and $\mathrm{E}$ as a lightly exposed subcohort. For the heavily exposed group no lower limit of exposure time was chosen, whereas only men with one year or longer exposure times were included in the lightly exposed group.

Subjects who were to be included in the study were mainly traced through personnel lists provided by the plant. For the earliest years, some were also traced by 3 interviewing some of the men who remembered their previous fellow workers.

\section{CLINICAL EXAMINATION}

All workers eligible were given a clinical examination at the department of occupational medicine of Tele- $\frac{\bar{\omega}}{\frac{1}{5}}$ mark County Hospital. The examination comprised $a_{\Omega} \underset{\Omega}{\Phi}$ medical history and an occupational history with spe-尺 cial emphasis on exposure to asbestos. Spirometry was registered on a recently calibrated Vitalograph? with the subject standing upright. Respiratory symp- $\vec{\omega}$ toms were recorded by means of a translated Medical ${ }^{\omega}$ Research Council questionnaire on chronic bronchitis. ${ }^{5}$ A $40 \times 40 \mathrm{~cm}$ chest $x$ ray film in frontal, lateral,,$?$ and $45^{\circ}$ oblique views of all subjects was taken at the + county hospital's department of radiology where the $c$ films were read by experienced radiologists.

Smoking habits were recorded at the clinical exam- ination. For the purpose of this study, those who had은 smoked regularly for at least one year were regarded as smokers. Smokers who had stopped smoking more ${ }_{\infty}$ than one year before the first examination were $\frac{\vec{\Phi}}{\mathbb{D}}$ regarded as ex-smokers.

Cohort members who were eligible have been followed up with yearly examinations from 1979-80 to 1985.

Gulsvik has investigated the prevalence of respixin $-v$ tory symptoms in a $6 \%$ sample of subjects aged between 15 and 70 from the city of Oslo. ${ }^{6}$ The results of that investigation were used as external reference material for the present study. A recording of lungo function in an asymptomatic group of subjects from $\mathbb{\Omega}$ the same Oslo study was also used in calculating age $=$ and smoking specific predicted spirometric values.

The statistical analysis of differences in the prevalence of respiratory symptoms and the frequency of lung function disturbances was based on the Mantel Haenszel test. ${ }^{7}$

\section{Results}

There were 153 men eligible for the study. Table 1 describes the heavily and lightly exposed subcohorts

Table 1 Mean age at first examination, mean age at first exposure to asbestos, duration of asbestos exposure, and smoking habits in the study population. (Ranges in parentheses)

\begin{tabular}{|c|c|c|c|c|c|c|c|c|c|}
\hline \multirow[b]{3}{*}{ Group } & \multirow{2}{*}{\multicolumn{2}{|c|}{$\begin{array}{l}\text { Age at first } \\
\text { examination }\end{array}$}} & \multirow{2}{*}{\multicolumn{2}{|c|}{$\begin{array}{l}\text { Age at first } \\
\text { asbestos exposure }\end{array}$}} & \multirow{2}{*}{\multicolumn{2}{|c|}{$\begin{array}{l}\text { Duration of } \\
\text { exposure }\end{array}$}} & \multicolumn{3}{|c|}{ Smoking habits } \\
\hline & & & & & & & \multirow{2}{*}{$\begin{array}{l}\text { Current } \\
\text { smokers } \\
(\%)\end{array}$} & \multirow{2}{*}{$\begin{array}{l}\text { Ex- } \\
\text { smokers } \\
(\%)\end{array}$} & \multirow{2}{*}{$\begin{array}{l}\text { Never } \\
\text { smoker } \\
(\%)\end{array}$} \\
\hline & Mean & $S D$ & Mean & $S D$ & Mean & $S D$ & & & \\
\hline $\begin{array}{l}\text { Heavily exposed group } \\
(n=40) \\
\text { Lightly exposed group } \\
(n=113)\end{array}$ & $\begin{array}{l}62 \cdot 9 \\
(38-87) \\
62 \cdot 3 \\
(32-85)\end{array}$ & $\begin{array}{l}9 \cdot 9 \\
9 \cdot 3\end{array}$ & $\begin{array}{l}27 \cdot 7 \\
(15-52) \\
31 \cdot 2 \\
(16-57)\end{array}$ & $\begin{array}{r}9 \cdot 2 \\
10 \cdot 5\end{array}$ & $\begin{array}{l}5 \cdot 3 \\
(0 \cdot 2-31) \\
13 \cdot 9 \\
(1-43)\end{array}$ & $\begin{array}{r}7 \cdot 1 \\
10 \cdot 7\end{array}$ & $62 \cdot 5$ & $25 \cdot 0$ & $\begin{array}{l}12 \cdot 5 \\
15 \cdot 9\end{array}$ \\
\hline
\end{tabular}


Table 2 Prevalence (\%) of asbestos related disorders in the study population at the initial examination in 1979-80.(1) and at the end of a four to five year follow up period (2)

\begin{tabular}{|c|c|c|c|c|c|c|}
\hline \multirow[b]{2}{*}{ Group } & \multicolumn{2}{|c|}{ Lung fibrosis \pm pleural plaques } & \multicolumn{2}{|c|}{ Pleural plaques only } & \multicolumn{2}{|c|}{$\begin{array}{l}\text { All asbestos related } \\
\text { findings }\end{array}$} \\
\hline & 1 & 2 & 1 & 2 & $I$ & 2 \\
\hline $\begin{array}{l}\text { Heavily exposed group }(n=40) \\
\text { Lightly exposed group }(n=113)\end{array}$ & $\begin{array}{l}47 \cdot 5 \\
10 \cdot 6\end{array}$ & $\begin{array}{l}57 \cdot 5 \\
12 \cdot 4\end{array}$ & $\begin{array}{l}12 \cdot 5 \\
12 \cdot 4\end{array}$ & $\begin{array}{l}25 \cdot 0 \\
24 \cdot 8\end{array}$ & $\begin{array}{l}60.0 \\
23 \cdot 0\end{array}$ & $\begin{array}{l}82 \cdot 5 \\
37 \cdot 2\end{array}$ \\
\hline All & $20 \cdot 3$ & $24 \cdot 2$ & $12 \cdot 4$ & $24 \cdot 8$ & $45 \cdot 1$ & 49.0 \\
\hline
\end{tabular}

in terms of mean age, mean age at first exposure to asbestos, mean duration of exposure, and smoking habits. The total duration of exposure was considerably shorter in the heavily exposed group where current smoking was also more prevalent; $62.5 \%$ compared with $46.9 \%$ in the lightly exposed group.

Table 2 presents the prevalence of asbestos related lung disorders among the study population observed at the initial examination and accumulated during the follow up period. The heavily exposed group had higher rates of lung fibrosis alone or in combination with pleural plaques, whereas the rates of "pleural plaques only" were similar in the two groups. Radiologically visible asbestos related disorders were observed in $98(64 \cdot 1 \%)$ of the 153 study subjects during the follow up period. Figure 1 shows the age adjusted prevalence of asbestos related disorders in the different groups of workers at the end of the follow up period. The 20 heaviest exposed workers (group A) who had mainly been employed in the fibre hut had a prevalence of lung fibrosis alone or in combination with pleural plaques and of pleural plaques only of $55.6 \%$ and $13.5 \%$ respectively. The corresponding figures for the 28 process operators from the incinerator hall (group D) were $6 \cdot 1 \%$ and $9 \cdot 4 \%$ respectively.

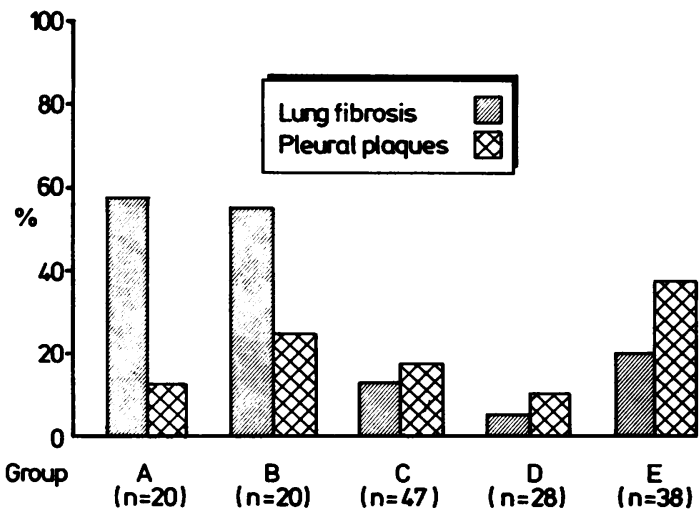

Fig 1 Age adjusted prevalence of asbestos related chest $x$ ray findings in different groups in study population at end of follow up. For explanation of groups $A-E$, see text.
As shown in fig 2, there was a higher prevalence of asbestos related disorders among workers first employed at the plant between 1930 and 1949 than among workers first employed between 1950 and 1970. The only prevalence which showed any relation to the duration of exposure to asbestos was for those with lung fibrosis in the light exposure group (fig 3 ).

Table 3 presents the prevalence of respiratory symptoms adjusted for age and smoking habits in relation to the radiographic findings in the study population compared with the external reference population. ${ }^{6}$ Before this comparison and the comparison of spirometric values, 15 study subjects with other current non-asbestos related lung diseases were excluded. Comparison with the external reference population was made only with study subjects aged under $70(<70)$, whereas all age groups were included in the internal comparison $(\geqslant 70)$. There were more respiratory symptoms in the group with lung fibrosis than in the other groups and in the study population as a whole compared with the external reference population, but most of the differences were not statistically significant on the $5 \%$ level.

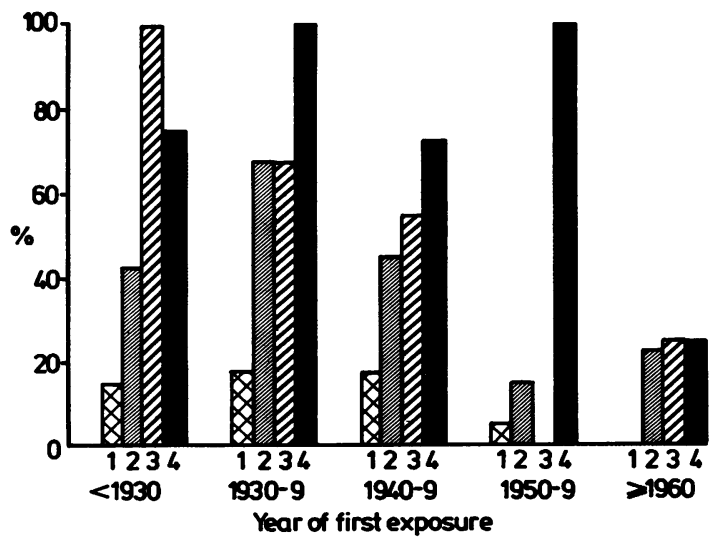

Fig 2 Prevalence of asbestos related chest $x$ ray findings in relation to time of first asbestos exposure. $1=$ lung fibrosis in lightly exposed group; 2 = pleural plaques in lightly exposed group; 3 = lung fibrosis in heavily exposed group;

4 = pleural plaques in heavily exposed group. 
Fig 3 Prevalence of asbestos related chest $x$ ray findings in relation to duration of asbestos exposure. For explanation of $1-4$, see figure 2 .

Figure 4 shows the percentages of subjects with positive answers to three or more of the questions on respiratory symptoms in the heavy and light exposure groups and for the different smoking categories. Among the lightly exposed never smokers, 5.6\% reported three or more symptoms whereas the corresponding figure for the heavily exposed current smokers was $28 \cdot 8 \%$.

Table 4 shows the prevalence of subjects with FVC and $\mathrm{FEV}_{1}$ under $90 \%$ and $80 \%$ of predicted and with $\mathrm{FEV}_{1} / \mathrm{FVC} \times 100(\mathrm{FEV} \%)$ under 70 in each of the groups and in relation to the radiographic findings. In addition to the 15 men with current non-asbestos related lung diseases, one man with a technically insufficient spirometry was also excluded before this comparison. There was a statistically significant excess in the prevalence of FEV 1 under $80 \%$ of predicted and FEV\% under 70 in the group with lung

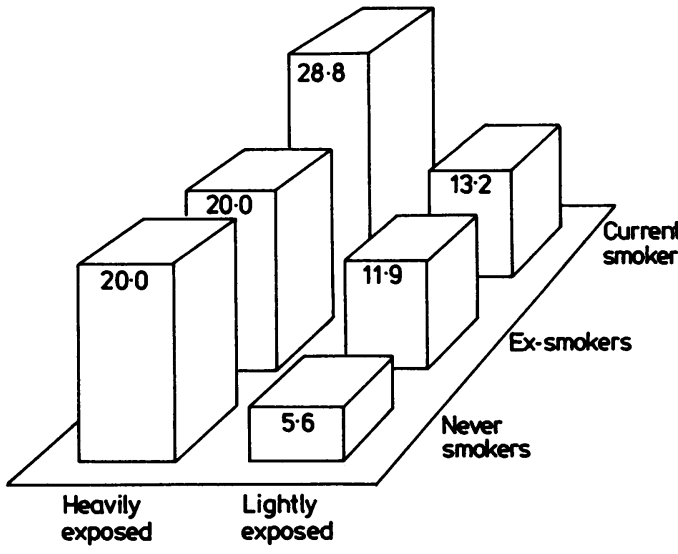

Fig 4 Percentages of subjects with three or more positive os answers to questions about respiratory symptoms in heavily and lightly exposed subcohorts and in relation to smoking habits.

fibrosis compared with the group with normal chesf $x$ ray films. In this regard, no statistically significant differences could be observed between the lightly an heavily exposed groups.

Figure 5 shows the development of the matero observed and predicted values (in BTPS) for FVC 更 d $^{2}$ $\mathrm{FEV}_{1}$ in relation to the radiographic findings for 91 subjects who were followed up for four or mare years from the first examination. None of th observed values was below the predicted minus tw\& standard deviations. The observed mean FVC shows a steeper fall than predicted in all groups, whereast the same pattern is only present among those with normal chest $x$ ray films for $\mathrm{FEV}_{1}$.

Table 5 presents the age adjusted prevalence of crepitations at chest auscultation. The group with pleural plaques only or in combination with lung fibrosis and the group with lung fibrosis only both

Table 3 Age adjusted and smoking adjusted prevalence (\%) of respiratory symptoms in the study population (I-III) compared with an external reference population (IV)

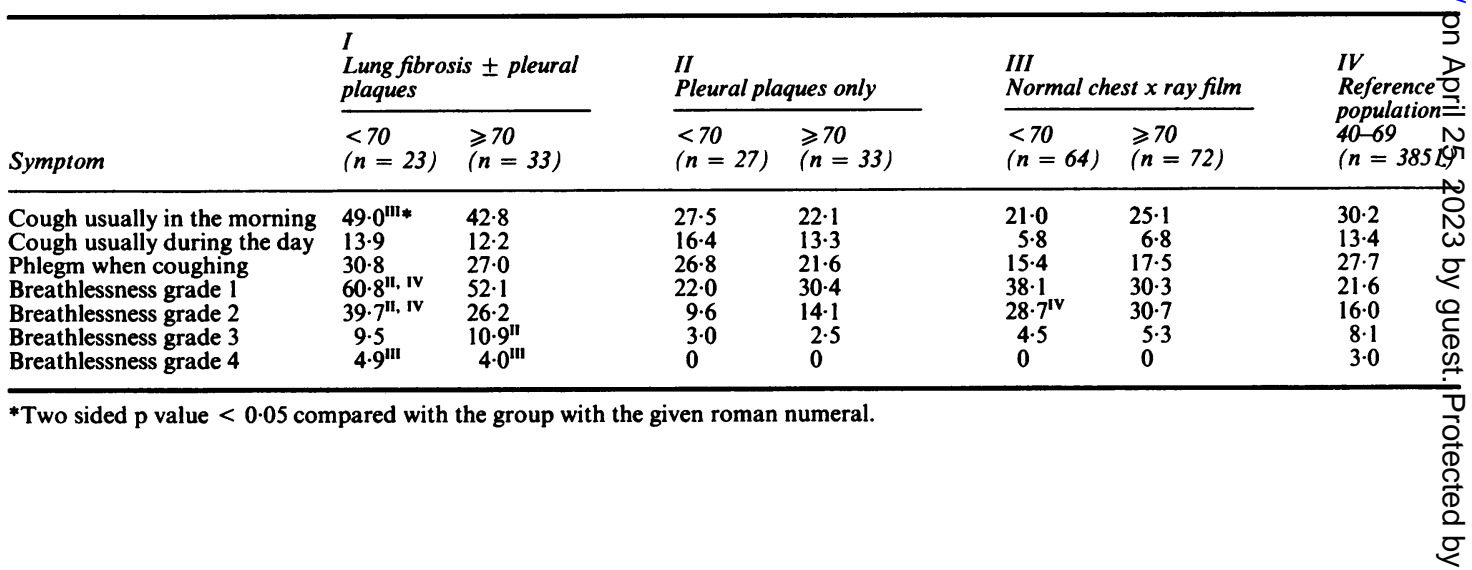


Table 4 Percentages of subjects from the study population with FVC and FEV 1 under $90 \%$ or under $80 \%$ of predicted and $F E V_{1} / F V C \times 100(F E V \%)$ under 70 at the initial examination

\begin{tabular}{|c|c|c|c|c|c|}
\hline Group & $\begin{array}{l}F V C \\
<90 \%\end{array}$ & $\begin{array}{l}F V C \\
<80 \%\end{array}$ & $\begin{array}{l}F E V_{1} \\
<90 \%\end{array}$ & $\begin{array}{l}F E V_{1} \\
<80 \%\end{array}$ & $\begin{array}{l}F E V \% \\
<70\end{array}$ \\
\hline $\begin{array}{l}\text { (I) Lung fibrosis } \pm \text { pleural plaques }(n=29) \\
\text { (II) Pleural plaques only }(n=34) \\
\text { (III) Normal chest } x \text { ray film }(n=74)\end{array}$ & $\begin{array}{l}55 \cdot 2 \\
50 \cdot 0 \\
45 \cdot 9\end{array}$ & $\begin{array}{l}31 \cdot 0 \\
14 \cdot 7 \\
20 \cdot 3\end{array}$ & $\begin{array}{l}62 \cdot 1^{111 *} \\
50 \cdot 0 \\
37 \cdot 8\end{array}$ & $\begin{array}{l}41 \cdot 4^{\mathrm{III}} \\
23 \cdot 5 \\
20 \cdot 3\end{array}$ & $\begin{array}{l}34 \cdot 5^{\mathrm{III}} \\
17 \cdot 6 \\
16 \cdot 2\end{array}$ \\
\hline $\begin{array}{l}\text { Heavily exposed group }(n=34) \\
\text { Lightly exposed group }(n=103)\end{array}$ & $\begin{array}{l}41 \cdot 2 \\
47 \cdot 6\end{array}$ & $\begin{array}{l}14 \cdot 7 \\
23 \cdot 3\end{array}$ & $\begin{array}{l}50 \cdot 0 \\
44 \cdot 7\end{array}$ & $\begin{array}{l}26 \cdot 5 \\
25 \cdot 2\end{array}$ & $\begin{array}{l}29 \cdot 4 \\
19 \cdot 4\end{array}$ \\
\hline
\end{tabular}

*Two sided $\mathrm{p}$ value $<0.05$ compared with the group with the given roman numeral.

Table 5 Age adjusted prevalence (\%) of subjects from the study population with crepitations registered at chest auscultation

\begin{tabular}{llll}
\hline Pleural plaques only $(n=36)$ & $\begin{array}{l}\text { Pleural plaques } \pm \text { lung } \\
\text { fibrosis }(n=32)\end{array}$ & Lung fibrosis only $(n=4)$ & Normal chest $x$ ray film $(n=81)$ \\
\hline $58 \cdot 5$ & $69 \cdot 1^{*}$ & $67 \cdot 2^{*}$ & $40 \cdot 5$ \\
\hline
\end{tabular}

*Two sided $\mathrm{p}$ value $<0.05$ compared with the group with normal chest $x$ ray films.

show a statistically significant increase in crepitations compared with the group with normal chest $x$ ray films.

During the follow up period from 1979 to 198531 of the study subjects died; their causes of death are given in table 6 . In addition to the cases of cancer in the table, one man who developed nasal cancer in 1982 and another who developed lung cancer in 1985 were still alive at the end of 1985 .

\section{Discussion}

With the study from a United States chemical plant conducted by Lilis et al, ${ }^{1}$ the results of the present study provide evidence for an appreciable risk of nonmalignant asbestos related diseases among chemical workers with frequent indirect exposures to asbestos.

The cross sectional character of the study may have

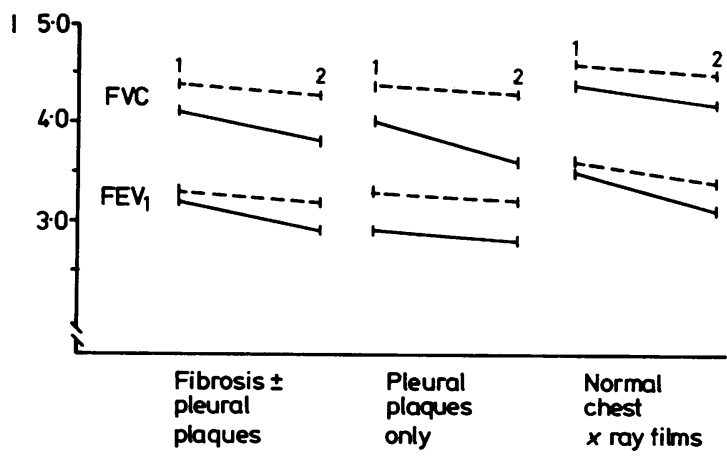

Fig 5 Mean observed spirometric values $\longmapsto$ (in $B T P S)$ and mean predicted values $\vdash \longrightarrow \longrightarrow$ in relation to radiographic findings at initial examination (1) and at the end of a four to five years follow up period (2). resulted in uncontrolled selection. Probably a larger proportion of subjects with asbestos related injuries died before the study took place than study subjects without such injuries. Such selection may have led to a reduced prevalence of asbestos related disorders, respiratory symptoms, and disturbances in lung function.

There was a positive relation between the estimated degree of exposure and the prevalence of asbestos related chest $x$ ray abnormalities (fig 1 ), whereas no such relation was observed between the duration of exposure and the prevalence of such disorders (fig 3). From the occupational histories of the study subjects it is known that some of the workers with the heaviest exposures had the shortest exposure times, and this may partly explain this last feature.

The number of subjects with radiologically recognised asbestos related disorders increased during the follow up period (table 2). In addition to some true incident cases, some apparent incident cases may also be due to the fact that the oblique view $x$ ray films were taken at a later occasion than at the initial examination in some cases.

Table 6 Causes of death among 31 cohort members who died during the observation period from 1980 to 1985

\begin{tabular}{lc}
\hline Cause of death & No \\
\hline Cardiovascular diseases & 16 \\
Lung cancer & 2 \\
Pleural malignant mesothelioma & 2 \\
Stomach cancer & 1 \\
Pulmonary asbestosis & 1 \\
Infectious lung diseases & 2 \\
Other infectious diseases & 1 \\
Chronic right heart failure & 1 \\
"Sudden death" & 3 \\
Unknown & 2 \\
\hline
\end{tabular}


The lower prevalence of asbestos related disorders with later date of first exposure may partly be due to improvement of working conditions in the later years and partly to long latency of asbestos related diseases. $^{89}$

In some studies an increased prevalence of respiratory symptoms and of impairment in lung function has been observed among subjects with pleural plaques only. ${ }^{10-14}$ Though there is a non-significant tendency, the present study does not provide any strong evidence for increased prevalence of respiratory symptoms among study subjects other than those with lung fibrosis.

In common with a Swedish study of asbestos cement workers ${ }^{15}$ the present study shows a raised prevalence of respiratory symptoms among all asbestos exposed subjects regardless of their radiographic findings. For the present study population, however, possible confounding from exposure to other lung irritating agents must also be considered.

When manual workers are compared with the general population the comparability is influenced by a healthy selection of workers. Together with the cross sectional character, this phenomenon has probably influenced the results regarding the prevalence of respiratory symptoms and lung function impairment in the present study.

During an observation period from 1953 to 1980 a study of workers from the same plant showed an increased incidence of lung cancer with 17 cases observed and 3.8 cases expected ${ }^{4}$ and four cases of pleural and one case of peritoneal malignant mesothelioma. The present follow up has provided three more cases of lung cancer and two of malignant pleural mesothelioma.

I gratefully acknowledge the cooperation of the staff of the Health Department at Norsk Hydro, Porsgrunn Fabrikker, in particular Jan Rosenberg and Irene Fritzon. Sverre Langård has helped as an advisor during the study and with constructive criticism of the manuscript. I also thank Unni Danielsen and Karin Theie for secretarial help, Patricia Flor for linguistic help, and nurse Liv Bruun for cooperation in conducting the clinical examinations. I have been engaged as a fellow of the Norwegian Cancer Societz since January 1985.

\section{References}

1 Lilis R, Daum S, Anderson H, Sirota M, Andrews G, Selikoff If Asbestos disease in maintenance workers of the chemicat industry. Ann NY Acad Sci 1979;330:127-35.

2 Bittersohl G, Ose H. Zur Epidemiologie des Pleuramesothelioms $Z$ Gesamte Hyg 1971;17:861-4.

3 Ose H, Bittersohl G. Zur Epidemiologie der Pleura-Asbestose. $\bar{Z}$ Erkr Atmungsorgane 1972;136:165-74.

4 Hilt B, Rosenberg J, Langård S. Asbestos exposure, smoking్ habits, and cancer incidence among production and mainte@ nance workers in an electrochemical plant. $\mathrm{Am} \mathrm{J}$ Ind $\mathrm{Me}$ 1985;8:565-77.

5 Medical Research Council's Committee on Research int Chronic Bronchitis. Questionnaire on respiratory symptoms London: Medical Research Council, 1966.

6 Gulsvik A. Obstructive lung disease in an urban population. Oslo Rikshospitalet, Department of Lung Diseases, 1979. (Thesis

7 Mantel N, Haenszel W. Statistical aspects of the analysis of data from retrospective studies of disease. J Natl Cancer Inson 1959;32:719-48.

8 Hillerdal G. Pleural plaques in a health survey material. Fręㅁำ quency, development and exposure to asbestos. Scand J RespiB Dis 1978;59:257-63.

9 Selikoff IJ, Hammond EC, Seidmann H. Latency of asbestos dis ease among insulation workers in the United States and Can ada. Cancer 1980;46:2736-40.

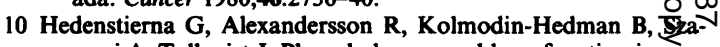
mosi A, Tollqvist J. Pleural plaques and lung function in cone struction workers exposed to asbestos. Eur $J$ Respir 1981;62:111-22.

11 Hilt B, Kjuus H, Langård $S$. Lungenfunktion un Atemwegssymptome bei Patienten mit pulmonalen Asbes tosen und asbestinduzierten Pleuraplaques. In: VIth inter-D national pneumoconiosis conference, Bochum, 1983. Vol ? Geneva: International Labour Organisation, 1984:911-23.

12 Hilt B, Lien J Th, Lund-Larsen PG. Lung function an $₫$ respiratory symptoms in subjects with asbestos-related disorders-a cross-sectional study. Am J Ind Med (in press)

13 Lilis R, Lerman Y, Malkin J, Selikoff IJ. Interstitial pulmonary. fibrosis: comparative prevalence and symptoms in insulation workers with over 30 years from onset of exposure. In: VIt $\$$ international pneumoconiosis conference Bochum, 1983. Vol 2? Geneva: International Labour Organisation, 1984:697-715. 윽

14 Sandén $\AA$, Larsson S, Lavenius B. Asbestexponerade varvsar:betare-en tvärrsnittsstudie. Läkartidningen 1984;81:1959-6\%

15 Ohlson C-G, Rydman T, Sundell L, Bodin L, Hogstedt C. Decreased lung function in long-term asbestos cement workers: a cross-sectional study. Am J Ind Med 1984;5:359-66. 